the health and social services at present provided by local authorities has also been emphasized. Without a medical man committed to the measurement, planning, and development of all services for the prevention and treatment of disease in each administrative area an integrated health service cannot be achieved.

The main elements in the professional training of the specialist in community medicine are stated in the Todd report thus: epidemiology, statistics, medical sociology, operational research, and the organization of medical care and administration (management). The report also recommends that doctors should not commit themselves to a career in community medicine too soon but should work in the clinical services, both in hospital and in general practice, for some years first of all. Epidemiological studies to measure the efficiency of existing services and to identify new needs will form the basis of the new community health unit and will require the use of statistical and computer techniques and record linkage. It is from this that the knowledge will come for the rational planning and future development of the integrated services.

The formation of a joint Faculty of Community Medicine by the Royal College of Physicians in the United Kingdom reported last week ${ }^{5}$ is therefore timely and welcome. A provisional council has met under the chairmanship of Dr. Wilfred Harding and a provisional education committee has also been set up. Later in the year the Faculty will receive applications from doctors wishing to become founder members. As the Faculty gets going it will doubtless do more than concern itself with the education of practitioners in its specialty, for by its presence it will help the community physician to be recognized from the outset as a medical specialist working alongside his clinical colleagues.

In many parts of the country the planning of the community health services is a matter of some urgency requiring the development of health centres and the deployment of non-medical staff to work with the general practitioners. There is also a need to co-ordinate the work in the community with that of the hospitals, which will certainly mean that some of the community physician's staff will be working in these hospitals. Many other activities and responsibilities, some new and some old, will fall to the lot of the community physician, and some of these have been discussed recently. 67 What he will eventually achieve will largely depend on his own initiative and abilities and on the resources made available to him in the new administrative structure of the national health services. It is certainly a challenge that many medical officers of health at present, and it is to be hoped many able young doctors in the future, will be ready to accept.

1 Royal Commission on Medical Education 1965-68, Report, Cmnd. 3569 London, H.M.S.O., 1968. Chief Medical Officer of the Department of Health and Social Security,
On the State of the Public Health, 1959. London, H.M.S.O., 1960.

3 Chief Medical Officer of the Department of Health and Social Security,

On the State of the Public Health, 1967. London, H.M.S.O., 1968.

Godber, G. E., Practitioner, 1968, 201, 162.

5 British Medical fournal, 1971, 2, 413 .

6 Gooding, D. G., Lancet, 1970, 1, 71 i.

7 Parry, W. H., paper presented at Royal Socicty of Health mecting, November 1970, unpublished.

\section{Eyes in the Dark}

When a mere flick of the finger can produce light in any dark corner of the house, it is easy to overlook the fact that our eyes are in many ways akin to those of nocturnal animals. In particular, they are endowed with a homoeostatic property which enables them to preserve their function as detectors of light even in poor illumination. This is what is meant by dark-adaptation. The assimilation to darkness takes over half an hour to achieve, as might be expected from a rhythm which is probably linked to the rate at which the sun sets. The quantification of the phenomenon is tedious, ${ }^{1}$ for it involves the measurement of a constant light-dependent response, for example, the smallest amount of light which a patient can see after a given time in the dark-or the amount of light necessary to elicit a given electrical response of the eye.

Measurement of long-term dark-adaptation gives information on the function of the retinal rods. These are used for night vision and vastly outnumber the cones, which dominate day vision. In the past impaired dark-adaptation was taken as prima facie evidence for malfunction of the rods. Avitaminosis is the classical example. In its early stage the loss of dark-adaptation is reversible because it is probably caused only by a loss in concentration of rhodopsin-the substance which converts light into electric impulses in the optic nerve. But in the more advanced stage the disease is irreversible because the rods are destroyed. 2 The syndrome of nyctalopia or night-blindness also used to be linked with an absence of rhodopsin, but it has recently been shown ${ }^{3}$ that the concentration and photodynamics of rhodopsin of congenitally night-blind patients can be normal, even though their dark-adaptation is gravely impaired. As darkadaptation has a photo-chemical ${ }^{4}$ and a nervous ${ }^{5}$ component, it is evident that a lesion in the rods or other parts of the retina may cause it.

The recent discovery ${ }^{6}$ that loss of dark-adaptation can occur unilaterally is interesting, especially as in one of the two cases described it was temporary. This patient was a married woman of 50 . Her right eye failed to show any rod adaptation for four months, and electro-diagnostic tests confirmed the symptom. Complete recovery followed and has been maintained for two years. The other patient was a man of 48 whom it proved impossible to follow up. No measurement of the rhodopsin levels are reported for these cases and the authors believe that the lesions occurred probably in the retinal bipolar layer.

These patients were among 2,000 examined, so that the condition may have a relatively high incidence. It should be stressed that the symptoms were described by the patients in the absence of any other complaint. A certain amount of sophistication and perceptiveness is needed to compare what the left and right eyes see separately: many people, for instance, have difficulty in closing each eye in turn. An earlier German report ${ }^{7}$ estimated that up to $10 \%$ of the normal population may have impaired dark-adaptation even though day vision may be normal.

It would appear that the problem is of more than academic interest. Adequate dark-adaptation is of paramount importance in driving at night. There is no information on the incidence of either unilateral or bilateral impairment of this faculty largely because the law assumes that if vision is normal during the day it must be normal also at night. This is an example of research being "pure" because the community refuses to apply its results. There is little doubt, however, that much can be done to accelerate the clinical assessment of the factors involved. For example the formation of rhodopsin can be gauged fairly accurately by means of fundus reflectometry after two or three minutes' darkness (as compared with ten times as much for subjective techniques). Photographic fundus reflectometry is 
now being developed for use under clinical conditions, and this, coupled to electro-diagnosis, should prove helpful for the provision of screening facilities. At the same time it is important to clarify the clinical picture, to learn more about the several causes of the condition, and to determine whether there is, for example, an age factor, as this would help to get the problem into some sort of perspective.

\footnotetext{
1 Sy:stcm of Ophthalmology, cd. Sir S. Duke-Elder, Vol. 4. London, Kimpton, 1969.

Dowling, J. E., American fournal of Ophthalmology, 1960, 50, 875 Carr, R. E., Ripps, H., Sicgel, I. M., and Wealc, R. A., Investigative Ophthalmology, 1966, 5, 497.

Rushton. W. A. H.. Joumal of Physiology, 1961, 156, 193.

Arden, G. B., and Wcalc, R. A., foumal of Physiology, 1954, 125, 417. Kclsey, J. H., and Arden, G. B., British fournal of Ophthalmology $1971,55,38$.

Pcukcrt, E., Zentralblatt für Verkehrs-Medizin, Vcrkchrs-Psychologic und angrenzcnde Gcbiete, 1958, 4, 202.
}

\section{Deaths from Tuberculosis}

Almost all tuberculous patients can be cured by modern chemotherapy. Advanced methods for diagnosis and treatment of the disease are generally available throughout Britain. It is therefore surprising that 2,000 deaths annually are attributed to the disease, a quarter of them undiagnosed before death.

A report by the Research Committee of the British Thoracic and Tuberculosis Association ${ }^{1}$ shows that many of these deaths are avoidable. An investigation of deaths occurring during a three-month period in 1968 disclosed 263 people whose death was due to active tuberculosis. At least one avoidable factor responsible for or contributing to death was identified in $211(80 \%)$.

Diagnostic error occurred in $20 \%$ of the patients in whom diagnosis was made only after death. This error resulted most commonly from a mistaken assumption of the rarity of tuberculosis and failure to recognize unusual forms of the disease. The usual mistake in general practice was to attribute respiratory symptoms too readily to chronic bronchitis without excluding tuberculosis and other disease by chest radiography. Ready access for the general practitioner to chest $x$-ray services is a continuing necessity. Mismanagement in hospital occurred mainly in elderly patients. In this series $40 \%$ of the deaths were in patients aged over 70 years. Omission of chest radiography in patients predisposed to tuberculosis, including diabetics, alcoholics, and those receiving long-term corticosteroids, was another important error in hospital practice.

Widespread disease in old people is too readily attributed to carcinomatosis in the absence of histological confirmation, and such patients are inadequately investigated for tuberculosis. Generalized tuberculosis in the elderly may lack the characteristic features of generalized miliary tuberculosis. They present with a severe systemic illness, insidious in inset and progress, in which general malaise, wasting, and fever occur in the absence of miliary mottling and choroidal tubercles. The tuberculin test is sometimes negative, and bacteriological or histological proof of the disease is usually difficult to obtain. This cryptic disseminated tuberculosis is best diagnosed by a therapeutic trial of isoniazid with para-amino salicylic acid. ${ }^{2}$

Extrapulmonary forms of tuberculosis are rare in British patients. In contrast, tuberculosis in Asian and African im- migrants often occurs as miliary, peritoneal, intestinal, and lymph-node disease. It may present as an obscure condition, and the cause is easily overlooked. With immigrant patients especially it is important to be alert to the possibility of unusual forms of tuberculosis.

Medical care was regarded as unsatisfactory in $57 \%$ of the patients in the series. Most commonly chemotherapy was inadequate. The rules of chemotherapy are deceptively simple but errors often occur in the prescribing or administration of the drugs, and the patient may fail to take them as prescribed because of forgetfulness, indolence, or ignorance. Long-term domiciliary chemotherapy needs to be closely supervised by a skilled chest clinic team, which should include a specially trained health visitor.

The patients were judged to have been largely responsible for their own deaths from tuberculosis in $40 \%$ of the series. The most clearly defined factors associated with the patients' failures of co-opcration were old age, mental disorder, and alcoholism. In all these groups there is a tendency for the patient to ignore symptoms or to attribute them to old age or chronic disorders from which the patient knows himself to be suffering. The community welfare services have an important part to play here in maintaining contact with aged people living alone and neglected at home and in the supervision of the inmates of common lodging houses or reception centres, some of whom are alcoholics or mentally ill.

This survey shows that in the prevention of tuberculosis today more support for the immigrant by the community services is needed in view of the high notification rates in this group. And the commonest avoidable factor leading to death was failure to observe generally accepted standard practice. It seems that undergraduate and postgraduate medical education in Britain is deficient in the field of tuberculosis.

\section{${ }^{1}$ British Thoracic and Tuberculosis Association, Tubercle, 1971, 52, 1.
2 Proudfoot, A. T., Akhtar, A. J., Douglas, A. C., and Horne, N. W., British Medical fournal, 1969, 2, 273.}

\section{Gas Gangrene of the Eye}

The words "gas gangrene" carry with them echoes of the first world war and that sad catalogue of battle casualties with their crepitating limbs and inexorable fate. Though in the antibiotic era in peacetime Britain the infection is rarely seen, it does sometimes attack the eye. And even if it is recognized and treated at the earliest stage the eye is almost inevitably lost.

Two recent case reports, one from Exeter and one from Cape Town, remind us of this mortifying risk. In both cases foreign bodies entered the eye while the patient was hammering. The first patient was adjusting his car wheel, and the second was a boy who was working in a dirty backyard. In both cases all seemed well for a few hours, but within a day the patient was febrile, with an indurated orbit, brownish mucopus welling from the eye, and a pathognomonic bubble of gas lying beneath the cornea. Within a few days the eye in both cases had to be eviscerated, and after intensive penicillin treatment the orbital induration and oedema slowly subsided. Hyperbaric oxygen was given to the boy, but its inhibiting effect on the spread of the clostridia was thought to work only in the extraocular tissues, because most intraocular structures are avascular and 